\title{
Fabrication of Cobalt Nanowires by Electroless Deposition under External Magnetic Field
}

\section{$\operatorname{AUTHOR}(\mathrm{S})$ :}

Balela, Mary Donnabelle L.; Yagi, Shunsuke; Matsubara, Eiichiro

\section{CITATION:}

Balela, Mary Donnabelle L....[et al]. Fabrication of Cobalt Nanowires by Electroless

Deposition under External Magnetic Field. JOURNAL OF THE ELECTROCHEMICAL SOCIETY 2011, 158(4): D210-D216

ISSUE DATE:

2011

URL:

http://hdl.handle.net/2433/163418

RIGHT:

(C) 2011 ECS - The Electrochemical Society 


\section{Fabrication of Cobalt Nanowires by Electroless Deposition under External Magnetic Field}

Mary Donnabelle L. Balela, Shunsuke Yagi and Eiichiro Matsubara

J. Electrochem. Soc. 2011, Volume 158, Issue 4, Pages D210-D216. doi: 10.1149/1.3545065

Email alerting service
Receive free email alerts when new articles cite this article - sign up in the box at the top right corner of the article or click here

To subscribe to Journal of The Electrochemical Society go to: http://jes.ecsdl.org/subscriptions

(C) 2011 ECS - The Electrochemical Society 


\title{
Fabrication of Cobalt Nanowires by Electroless Deposition under External Magnetic Field
}

\author{
Mary Donnabelle L. Balela, ${ }^{*, z}$ Shunsuke Yagi, ${ }^{* *}$ and Eiichiro Matsubara \\ Department of Materials Science and Engineering, Kyoto University, Kyoto 606-8501, Japan
}

Metallic Co nanowires with a mean diameter of about $190 \mathrm{~nm}$ and lengths up to $160 \mu \mathrm{m}$ are prepared by electroless deposition (solution reduction) in propylene glycol at room temperature under external magnetic field. Co deposition behavior in propylene glycol is investigated by in situ monitoring of mixed potentials in conjunction with linear sweep voltammetry and the oxidationreduction potential of the $\mathrm{Co}(\mathrm{II}) / \mathrm{Co}$ redox pair is determined to be about $-0.54 \mathrm{~V}$ vs $\mathrm{Ag} / \mathrm{AgCl}$. When the mixed potential drops below the oxidation-reduction potential of the $\mathrm{Co}(\mathrm{II}) / \mathrm{Co}$ redox pair, small Co nanoparticles are generated in the solution and are magnetized in the presence of external magnetic field. Strong attractive dipolar interactions are induced along the magnetic field direction, which results in the assembly of Co nanoparticles to nanowires. The Co nanowires exhibit ferromagnetic properties at room temperature, with an enhanced coercivity of about 700 Oe possibly due to shape anisotropy. (C) 2011 The Electrochemical Society. [DOI: 10.1149/1.3545065] All rights reserved.

Manuscript submitted November 5, 2010; revised manuscript received December 29, 2010. Published February 23, 2011.

Control of the morphology of nanostructures is a critical aspect in the fabrication of electronic or mechanical devices and functional materials. ${ }^{1,2}$ For example, one-dimensional (1D) ferromagnetic nanostructures, such as nanowires and nanorods, have been attracting significant attention due to their large anisotropic magnetism, which is important for applications in permanent magnets and highdensity magnetic storage media. ${ }^{3-5}$ Its large surface area is also favorable for use as catalysts. ${ }^{6}$ On the other hand, Co oxide nanowires and nanotubes are currently being explored as possible electrode materials for lithium-ion batteries. ${ }^{7-9}$ In the past years, templatedirected synthesis routes have made considerable progress in the fabrication of well-aligned magnetic nanowires and nanorods with tunable diameter and length. ${ }^{2,10-14}$ However, such methods are not suitable for large-scale production since the preparation and the subsequent removal of templates are required. ${ }^{15-17}$ Against such background, the application of magnetic fields during solution reduction is recently being utilized to fabricate anisotropic nanostructures due to its simplicity and effectiveness. For example, $\mathrm{Fe}_{3} \mathrm{O}_{4}$ nanochains, ${ }^{18} \mathrm{Ni}-\mathrm{Co}$ alloy microwires, ${ }^{19,20} \mathrm{Co}$ nanosheets, ${ }^{21} \mathrm{Co}$ nanorods, ${ }^{5,15,22,23}$ and $\mathrm{Ni}$ nanowires ${ }^{4,6,16}$ have already been prepared by magnetic-field-assisted hydrothermal and solvothermal syntheses. However, methods, such as hydrothermal and solvothermal processes, require high temperature, high pressure, or long reaction time to fabricate 1D nanostructures. ${ }^{24}$

In the present work, we report a rapid and inexpensive approach to the preparation of Co nanowires at room temperature with a fast reaction rate and a high yield. The synthesis of long and rigid Co nanowires is performed by electroless deposition (solution reduction) in propylene glycol under an external magnetic field. Co nanowires with a mean diameter of about $190 \mathrm{~nm}$ and lengths up to $160 \mu \mathrm{m}$ are fabricated at ambient conditions (normal pressure and room temperature) without any templates. The reduction of $\mathrm{Co}$ (II) ions in the reaction system is investigated by in situ mixed potential measurement in combination with linear sweep voltammetry, and the starting point of the reaction is determined. The formation of Co nanowires is studied by observing the morphological and structural evolution of the products. The effects of reaction conditions, such as magnetic field strength, amount of nucleating agent and concentration of reducing agent, on the size of Co nanowires are examined.

\section{Experimental}

The chemical reagents used in this work were analytical grade $\mathrm{Co}$ (II) acetate tetrahydrate $\left[\mathrm{Co}\left(\mathrm{C}_{2} \mathrm{H}_{3} \mathrm{O}_{2}\right)_{2} \cdot 4 \mathrm{H}_{2} \mathrm{O}\right]$, poly(ethylene glycol) $\left[\mathrm{PEG}, \mathrm{H}\left(\mathrm{OCH}_{2} \mathrm{CH}_{2}\right) \mathrm{nOH}, M_{\mathrm{w}}=20,000\right]$, propylene glycol

\footnotetext{
* Electrochemical Society Student Member.

** Electrochemical Society Active Member.

${ }^{\mathrm{z}}$ E-mail: balela.m@hw8.ecs.kyoto-u.ac.jp
}

(PG, $\mathrm{C}_{3} \mathrm{H}_{8} \mathrm{O}_{2}$ ), sodium hydroxide $(\mathrm{NaOH})$, chloroplatinic acid hexahydrate $\left(\mathrm{H}_{2} \mathrm{PtCl}_{6} \cdot 6 \mathrm{H}_{2} \mathrm{O}\right)$, hydrazine monohydrate $\left(\mathrm{N}_{2} \mathrm{H}_{4} \cdot \mathrm{H}_{2} \mathrm{O}\right)$, lithium perchlorate $\left(\mathrm{LiClO}_{4}\right)$, and ethanol $\left(\mathrm{C}_{2} \mathrm{H}_{6} \mathrm{O}\right)$ by Nacalai Tesque. $\mathrm{Co}$ (II) acetate tetrahydrate, $\mathrm{PEG}$, and $\mathrm{PG}$ acted as Co precursor, surfactant, and solvent, respectively. On the other hand, $\mathrm{H}_{2} \mathrm{PtCl}_{6} \cdot 6 \mathrm{H}_{2} \mathrm{O}$ and $\mathrm{N}_{2} \mathrm{H}_{4} \cdot \mathrm{H}_{2} \mathrm{O}$ served as nucleating agent and reductant. In a typical synthesis, two kinds of solutions, i.e., the metal ion solution and reducing agent solution, were prepared separately. First, $10 \mathrm{mmol}$ Co(II) acetate and $0.125 \mathrm{mmol}$ PEG were dissolved in $50 \mathrm{~cm}^{3} \mathrm{PG}$ while nitrogen gas $\left(\mathrm{N}_{2}\right)$ was bubbled at $50 \mathrm{~cm}^{3} \mathrm{~min}^{-1}$. Then, $25 \mathrm{~cm}^{3}$ of $1.0 \mathrm{M}\left(\mathrm{mol} \mathrm{dm}^{-3}\right) \mathrm{NaOH}-\mathrm{PG}$ solution was added to hydrolyze the $\mathrm{Co}$ (II) ions and adjust the $\mathrm{pH}$ to about 12 . This decreased the activity of $\mathrm{Co}$ (II) ions in the solution, which would favor the formation of small primary Co nanoparticles. Next, $10 \mathrm{~cm}^{3}$ of $2.5 \mathrm{mM}$ $\mathrm{H}_{2} \mathrm{PtCl}_{6}$-PG solution was added to the metal ion solution as a nucleating agent to provide heterogeneous nucleation sites for Co. As the reducing agent solution, $25 \mathrm{~cm}^{3}$ deaerated PG solution containing 4.0 $\mathrm{M} \mathrm{N}_{2} \mathrm{H}_{4}$ was prepared. The reducing agent solution was then mixed thoroughly with the metal ion solution in a $200 \mathrm{~cm}^{3}$ Pyrex beaker by mechanical stirring. The total solution had a volume of $115 \mathrm{~cm}^{3}$, with final concentrations of $0.087 \mathrm{M} \mathrm{Co}(\mathrm{II})$ acetate, $1.1 \mathrm{mM}$ PEG, 0.22 M NaOH, $0.22 \mathrm{mM} \mathrm{H}_{2} \mathrm{PtCl}_{6}$, and $0.87 \mathrm{M} \mathrm{N}_{2} \mathrm{H}_{4}$. The final $\mathrm{pH}$ remained about 12 , which would increase the reducing power of $\mathrm{N}_{2} \mathrm{H}_{4}$. The resulting solution was placed in a superconducting magnet (Japan Magnet Technology JMTD-10T100M) for $1 \mathrm{~h}$. The magnetic field strength was varied from 1 to $10 \mathrm{~T}$ by controlling the working electric current of the superconducting magnet. The synthesized nanowires were magnetically separated from the solution and ultrasonicated for $10 \mathrm{~min}$ in ethanol. This washing process was repeated 10 times to remove organic contaminants on the surface of the nanowires.

The morphology of the as-prepared products was observed by a field-emission-scanning electron microscope (JEOL JSM 6500-F) and a transmission electron microscope (TEM, JEOL JEM 2010). The mean diameter and lengths were determined by image analysis of 100 nanowires in each sample. The crystalline structure was investigated by X-ray diffraction (XRD, MAC Science M03XHF22) using $\mathrm{Cr} K \alpha$ radiation. The magnetic properties, such as saturation magnetization $\left(M_{\mathrm{s}}\right)$ and coercivity $\left(H_{\mathrm{c}}\right)$, were studied by a magnetic property measurement system superconducting quantum interference device (Quantum Design, Inc., MPMS SQUID XL) at room temperature using an applied field of $2 \mathrm{~T}$.

To investigate the reduction behavior of $\mathrm{Co}(\mathrm{II})$ ions in propylene glycol at room temperature, linear sweep voltammetry was performed using a potentiostat/galvanostat (Hokuto Denko, Co. Ltd., HA-151). A platinum ( $\mathrm{Pt}$ )-sputtered quartz crystal substrate $(0.196$ $\left.\mathrm{cm}^{2}\right)$ and a Pt sheet $\left(4 \mathrm{~cm}^{2}\right)$ were used as working and counter electrodes, respectively. The voltammogram was recorded from 0 to $-1.5 \mathrm{~V}$ at a potential sweep rate of $1 \mathrm{mV} \mathrm{s}^{-1}$. For the evaluation of 
(a) $0 \mathrm{~T}$

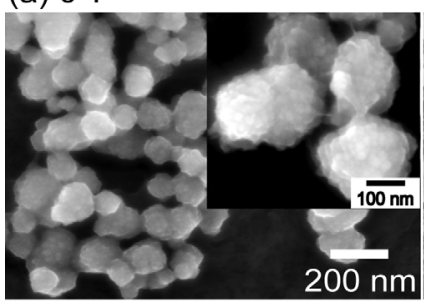

(b) $1 \mathrm{~T}$

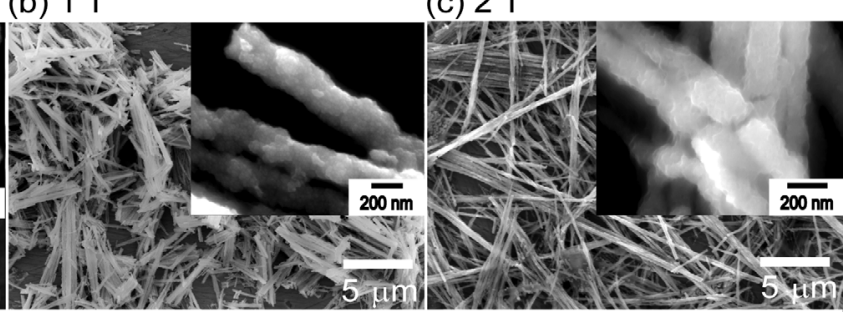

(d) $5 \mathrm{~T}$

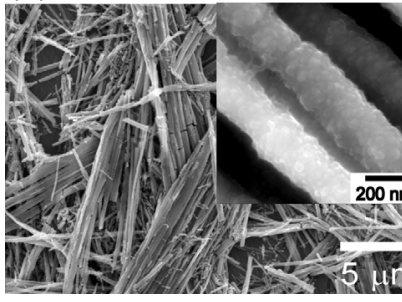

(e) $10 \mathrm{~T}$

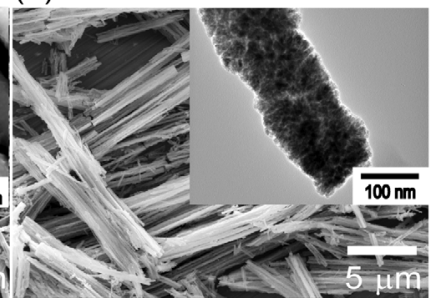

Figure 1. SEM and TEM images of products fabricated by electroless deposition of Co in a PG solution containing $0.087 \mathrm{M}$ $\mathrm{Co}$ (II) acetate, $0.22 \mathrm{M} \mathrm{NaOH}, 0.22 \mathrm{mM}$ $\mathrm{H}_{2} \mathrm{PtCl}_{6}$, and $0.87 \mathrm{M} \mathrm{N}_{2} \mathrm{H}_{4}$ at room temperature under a magnetic field of (a) 0 , (b) 1 , (c) 2, (d) 5, and (e) $10 \mathrm{~T}$. the electroinactive area of propylene glycol solution in the presence of $0.22 \mathrm{M} \mathrm{NaOH}$, the anodic and cathodic sweeps were conducted independently. Each sweep was started at the rest potential, which was observed to be reproducible. The anodic current was measured from the rest potential to $1.5 \mathrm{~V}$, while the cathodic current was recorded from the rest potential to $-1.5 \mathrm{~V}$. The time dependence of the mixed potential during electroless deposition of Co was also measured on a Pt QCM substrate to determine the starting point of the reaction. All mixed potential and linear sweep voltammetric measurements used $0.10 \mathrm{M} \mathrm{LiClO}_{4}$ as supporting electrolyte and a silver/silver chloride $(\mathrm{Ag} / \mathrm{AgCl})$ electrode (Horiba, 2565A-10T), immersed in $3.33 \mathrm{M}$ potassium chloride $(\mathrm{KCl})$ aqueous solution, as a reference electrode. In this paper, all potentials are reported against the potential of the $\mathrm{Ag} / \mathrm{AgCl}$ electrode.

\section{Results}

Figure 1 shows the scanning electron microscope (SEM) and TEM images of Co after electroless deposition (solution reduction) at room temperature under magnetic fields of 1-10 T. In the absence of magnetic field, only spherical Co nanoparticles of about $132 \mathrm{~nm}$ in mean diameter are obtained after $1 \mathrm{~h}$ reaction as shown in Fig. 1a. The Co nanoparticles are made up of several smaller nanoparticles as seen in the SEM image at higher magnification (see inset of Fig. 4a below). On the other hand, Co nanowires are formed when the reaction is conducted under an external magnetic field as in Figs. 1b-1e. Each Co nanowire has an almost uniform diameter over its entire length and seems to be composed of small spherical nanoparticles (see insets of Figs. 1b-1e). Although the Co nanoparticles prepared without magnetic fields are somewhat linearly agglomerated (Fig. 1a), the morphology of the nanowires obtained under external magnetic fields is evidently different from them. This suggests the remarkable effect of the magnetic field on the morphology of Co.

Under a field of $1 \mathrm{~T}$, Co nanowires with an average diameter of about $240 \mathrm{~nm}$ and lengths up to $30 \mu \mathrm{m}$ are obtained as shown in Fig. $1 \mathrm{~b}$. When the strength of magnetic field is increased, longer and smoother nanowires are formed. On the other hand, the mean diameter of Co nanowires is decreased. For example, Co nanowires about $190 \mathrm{~nm}$ in mean diameter and $160 \mu \mathrm{m}$ long are prepared under $10 \mathrm{~T}$. Bundlelike arrays of Co nanowires with parallel orientations are also observed at higher magnetic fields.

Figure 2 shows the corresponding XRD profiles of the samples. As shown in Fig. 2, the diffraction peaks of Co nanoparticles and nanowires are fundamentally attributed to both hexagonal closepacked (hcp) and face-centered cubic (fcc) Co. The strongest peak at $68.0^{\circ}$ and the very small peak at $80.5^{\circ}$ are attributed to 111 and $200 \mathrm{fcc} \mathrm{Co}$, respectively. The peak at $68.0^{\circ}$ has a shoulder at a higher scattering angle due to the $002 \mathrm{hcp}$ Co peak at $68.9^{\circ}$. The diffraction peaks of 100 and 101 hcp Co at $63.8^{\circ}$ and $73.6^{\circ}$, respectively, appear diffused in all XRD patterns. On the other hand, a very weak cobalt oxide $(\mathrm{CoO})$ peak at $55.5^{\circ}$ is seen due to $\mathrm{CoO}$ formed during XRD measurements or during washing. The crystallite sizes of the Co nanoparticles (about $15 \mathrm{~nm}$ ) and nanowires (10-12 nm) determined from the broadening of the $111 \mathrm{fcc}$ Co peaks by Scherrer's equation are much smaller than the apparent diameters of the samples. This indicates that the products are polycrystals, which corresponds well to the morphology observed by electron microscopy in Fig. 1.

The formation of Co nanowires in PG solution under an external magnetic field is investigated by sampling products at different reaction times. Figure 3 shows the SEM images of products obtained after $5,15,17$, and 20 min under $10 \mathrm{~T}$. During the early stage of reaction, large agglomerated particles with a broad size distribution of $100-500 \mathrm{~nm}$ are observed after $5 \mathrm{~min}$ (Fig. 3a). As the reaction proceeds to $15 \mathrm{~min}$, a mixture of short Co cylinders and spherical particles is obtained as shown in Fig. 3b. Interestingly, these cylinders and particles have smaller diameters than the particles observed after 5 min reaction. Short Co nanowires are then formed after $17 \mathrm{~min}$. Further increase in reaction time leads to longer and more rigid nanowires as shown in Figs. 5e and $5 \mathrm{f}$ below. The XRD patterns of the products obtained at different reaction times under $10 \mathrm{~T}$ are shown in Fig. 4. At 5 min, very weak hcp and fcc Co peaks are determined together with $\mathrm{CoO}$ peaks. The $111 \mathrm{CoO}$ peak at $55.5^{\circ}$ is

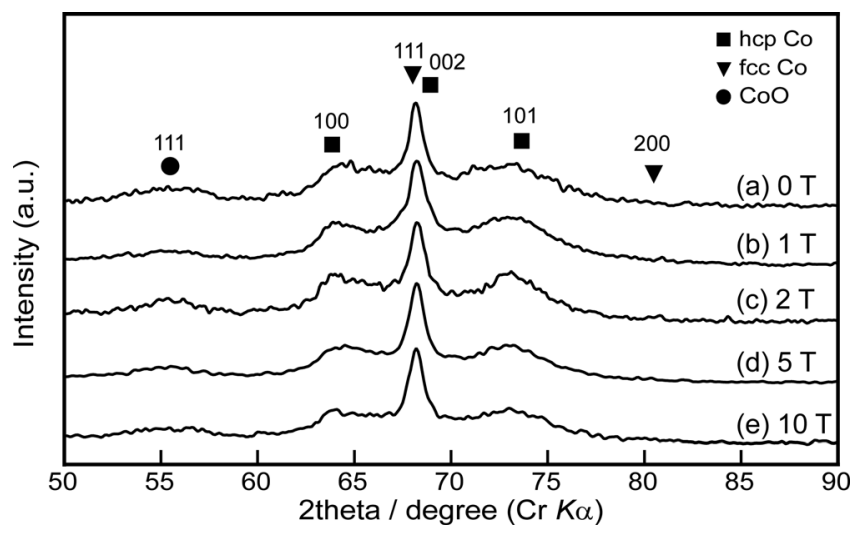

Figure 2. Corresponding XRD profiles of the samples prepared under (a) 0 , (b) 1 , (c) 2 , (d) 5, and (e) $10 \mathrm{~T}$ in a PG solution with $0.087 \mathrm{M} \mathrm{Co}$ (II) acetate $0.22 \mathrm{M} \mathrm{NaOH}, 0.22 \mathrm{mM} \mathrm{H}_{2} \mathrm{PtCl}_{6}$, and $0.87 \mathrm{M} \mathrm{N}_{2} \mathrm{H}_{4}$. 
(a)

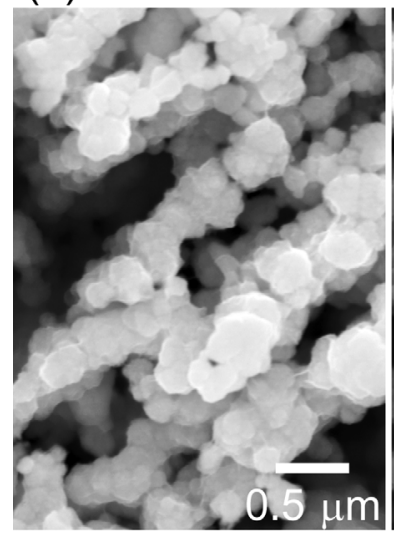

(b)

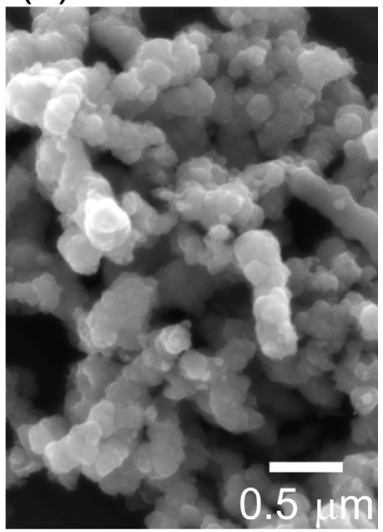

(d)
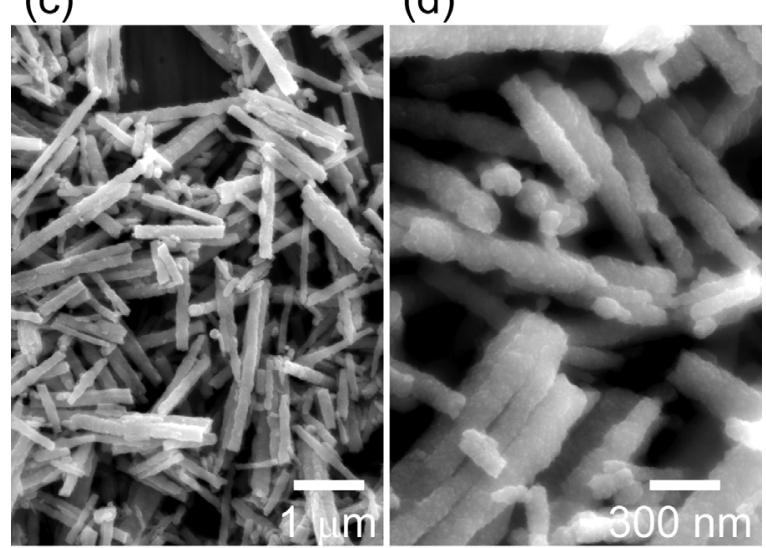

(e)

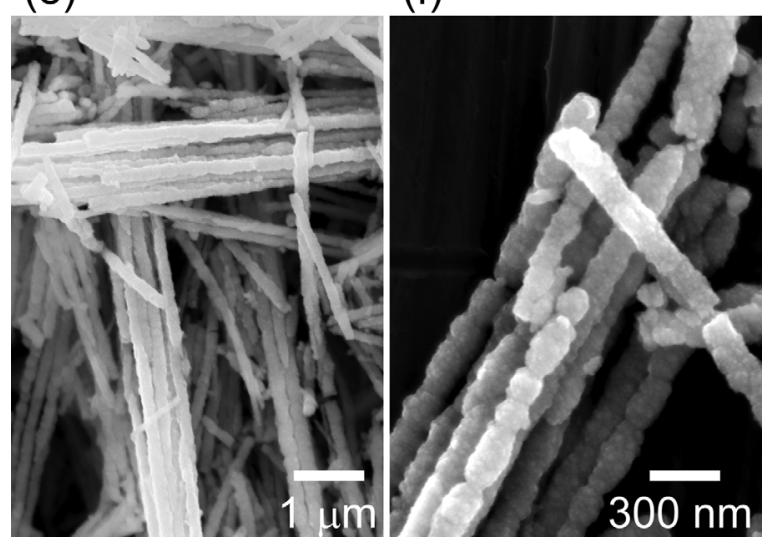

Figure 3. SEM images of products obtained at reaction times of (a) 5; (b) 15; (c), (d) 17; and (e), (f) 20 min during electroless deposition at room temperature under $10 \mathrm{~T}$ in a $\mathrm{PG}$ solution containing $0.087 \mathrm{M} \mathrm{Co}$ (II) acetate, 0.22 $\mathrm{M} \mathrm{NaOH}, 0.22 \mathrm{mM} \mathrm{H}_{2} \mathrm{PtCl}_{6}$, and $0.87 \mathrm{M} \mathrm{N}_{2} \mathrm{H}_{4}$.

clearly observed in Fig. 4a. The $200 \mathrm{CoO}$ peak at $65.0^{\circ}$ overlaps with the $100 \mathrm{hcp}$ and $111 \mathrm{fcc}$ Co peaks, which results in a broad shoulder on the left side of the $111 \mathrm{fcc}$ Co peak. As the morphology of the product changes to nanowires, the Co peaks grow sharper and the $\mathrm{CoO}$ peaks become broader. Additionally, the crystallite size of Co increases, which is evident from the decreased broadening of the Co peaks in Fig. 4b-4d.

\section{Discussion}

Electroless deposition of Co in propylene glycol solution at room temperature.- In the present system, the overall cobalt deposition in PG solution can be described as follows

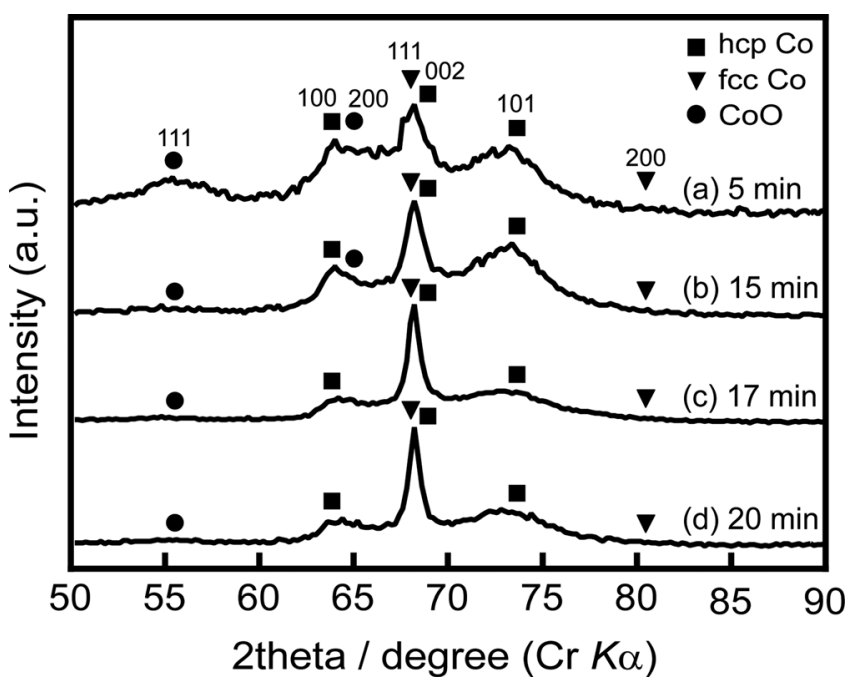

Figure 4. XRD patterns of products obtained at reaction times of (a) 5, (b) 15 , (c) 17 , and (d) $20 \mathrm{~min}$ during electroless deposition at room temperature under $10 \mathrm{~T}$ in a PG solution containing $0.087 \mathrm{M} \mathrm{Co}(\mathrm{II})$ acetate, $0.22 \mathrm{M}$ $\mathrm{NaOH}, 0.22 \mathrm{mM} \mathrm{H}_{2} \mathrm{PtCl}_{6}$, and $0.87 \mathrm{M} \mathrm{N}_{2} \mathrm{H}_{4}$.

$$
\begin{aligned}
& \mathrm{Co}(\mathrm{II})+[1 / 2] \mathrm{N}_{2} \mathrm{H}_{4}+2 \mathrm{OH}^{-} \rightarrow \mathrm{Co}+[1 / 2] \mathrm{N}_{2}+2 \mathrm{H}_{2} \mathrm{O} \\
& \mathrm{Co}(\mathrm{II})+2 \mathrm{~N}_{2} \mathrm{H}_{4}+2 \mathrm{OH}^{-} \rightarrow \mathrm{Co}+\mathrm{N}_{2}+2 \mathrm{NH}_{3}+2 \mathrm{H}_{2} \mathrm{O}
\end{aligned}
$$

where $\mathrm{Co}(\mathrm{II})$ represents all $\mathrm{Co}(\mathrm{II})$ species in the solution, e.g., $\mathrm{Co}^{2+}$, $\mathrm{Co}(\mathrm{OH})_{2}, \mathrm{Co}(\mathrm{OH})_{3}^{-}, \mathrm{Co}(\mathrm{OH})_{4}{ }^{2-}$, and $\mathrm{Co}\left(\mathrm{C}_{3} \mathrm{H}_{6} \mathrm{O}_{2}\right) .{ }^{25}$ The above reactions can be separated to cathodic (Co deposition) and anodic partial reactions $\left(\mathrm{N}_{2} \mathrm{H}_{4}\right.$ oxidation) that occur concurrently in the solution. ${ }^{26}$ There are other cathodic partial reactions, i.e., $\mathrm{Pt}$ deposition and $\mathrm{H}_{2}$ generation due to the reductive decomposition of $\mathrm{PG}$.

Due to lack of thermodynamic data on Co in organic solvents, thermodynamic calculations cannot be easily performed in the present case. Thus, linear sweep voltammetry is carried out to determine the oxidation-reduction potential of the $\mathrm{Co}(\mathrm{II}) / \mathrm{Co}$ redox pair $\left(E_{\mathrm{Co}(\mathrm{II}) / \mathrm{Co}}\right)$ in $\mathrm{PG}$ solution. Figure 5a shows the linear sweep voltammogram measured in a $115 \mathrm{~cm}^{3} \mathrm{PG}$ solution containing $0.087 \mathrm{M}$ $\mathrm{Co}$ (II) acetate and $0.22 \mathrm{M} \mathrm{NaOH}$ at a sweep rate of $1 \mathrm{mV} \mathrm{s}^{-1}$. At the start of the sweep, only nonfaradaic current flows through the system for the adsorption or the formation of electric double layers. As the applied potential becomes more negative, the electrode potential attains a value which allows reduction reactions to occur. ${ }^{27}$ As shown in Fig. 5a, the cathodic current starts to flow when the potential is decreased below about $-0.54 \mathrm{~V}$ vs $\mathrm{Ag} / \mathrm{AgCl}$. The measured cathodic current in a typical voltammogram is mainly a sum of the currents from all the reduction reactions, ${ }^{25}$ i.e., Co deposition and $\mathrm{H}_{2}$ generation due to reductive decomposition of PG. However, the onset of Co deposition observed at about $-0.54 \mathrm{~V}$ falls within the electroinactive range of a PG solution with $0.22 \mathrm{M} \mathrm{NaOH}$. This electroinactive range is from -0.80 to $0.90 \mathrm{~V}$ vs $\mathrm{Ag} / \mathrm{AgCl}$ as is indicated in Fig. 5b. In the presence of $0.22 \mathrm{M} \mathrm{NaOH}$, PG begins to be oxidized when the applied potential is more positive than $0.90 \mathrm{~V}$, whereas the reductive decomposition of PG occurs at potentials more negative than $-0.80 \mathrm{~V}$ resulting in the generation of $\mathrm{H}_{2}$ gas. At potentials below $-0.54 \mathrm{~V}$, only Co deposition occurs until the applied potential reaches $-0.80 \mathrm{~V}$, which is the onset of PG reduction. As the imposed voltage becomes more negative than $-0.80 \mathrm{~V}$, the cathodic current density progressively increases due to the concurrent $\mathrm{PG}$ reduction.

Figure 6 shows the changes in mixed potential with time during electroless deposition of Co in a PG solution containing $0.087 \mathrm{M}$ $\mathrm{Co}$ (II) acetate, $0.22 \mathrm{M} \mathrm{NaOH}, 0.22 \mathrm{mM} \mathrm{H}_{2} \mathrm{PtCl}_{6}$, and $0.87 \mathrm{M} \mathrm{N}_{2} \mathrm{H}_{4}$ at room temperature. From the thermodynamical viewpoint, Co can 

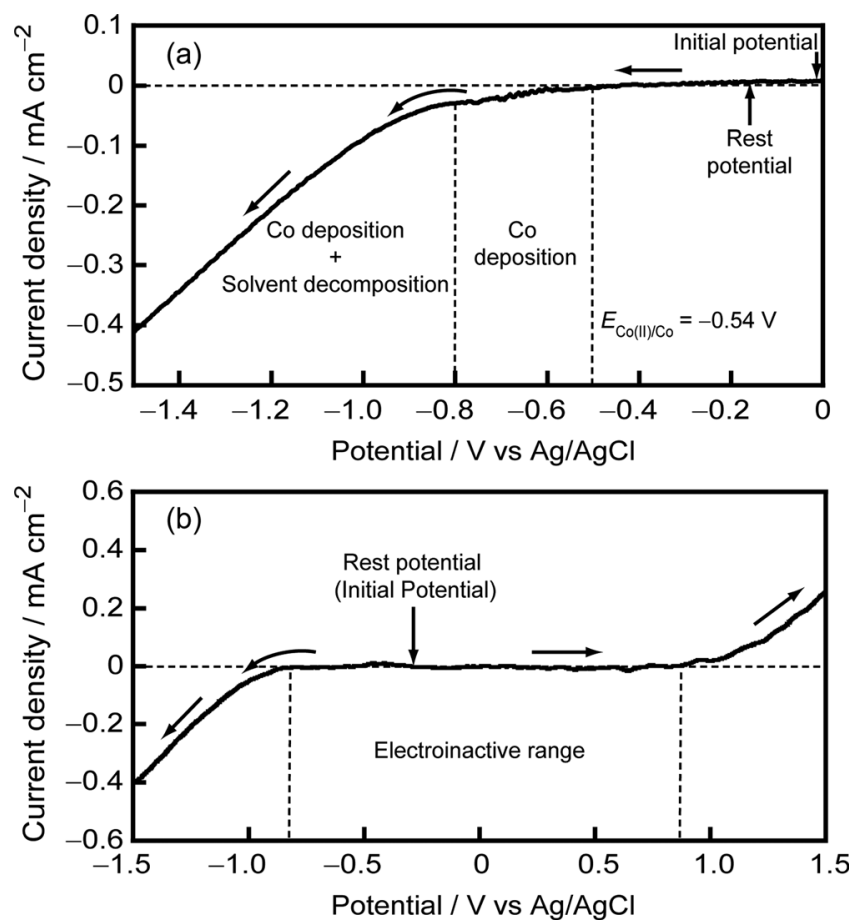

Figure 5. Linear sweep voltammograms measured on a Pt electrode of a PG solution (a) with $0.087 \mathrm{M}$ and (b) without $0.087 \mathrm{M} \mathrm{Co}$ (II) acetate. The voltammograms were recorded at room temperature with a scan rate of $1 \mathrm{mV} \mathrm{s}^{-1}$ in the presence of $0.22 \mathrm{M} \mathrm{NaOH}$ and $0.10 \mathrm{M} \mathrm{LiClO}_{4}$. The arrows along the current curves indicate the sweep direction.

only be deposited when the mixed potential is more negative than $E_{\mathrm{Co}(\mathrm{II}) / \mathrm{Co}}=-0.54 \mathrm{~V}$ vs $\mathrm{Ag} / \mathrm{AgCl}$ as determined from Fig. $5 \mathrm{a} .{ }^{26} \mathrm{The}$ mixed potential drops below $-0.54 \mathrm{~V}$ after 5 min as shown in Fig. 6, and the solution color starts changing from pink to black. Around this time, $\mathrm{Pt}(\mathrm{IV})$ ions from the nucleating agent $\mathrm{H}_{2} \mathrm{PtCl}_{6}$ are reduced to $\mathrm{Pt}$ since the $\mathrm{Pt}(\mathrm{IV}) / \mathrm{Pt}$ redox pair is more positive than those of $\mathrm{Co}(\mathrm{II}) / \mathrm{Co}$ (about $-0.54 \mathrm{~V})$ and $\mathrm{H}(\mathrm{I}) / \mathrm{H}_{2}$ redox pairs $(-0.80 \mathrm{~V})$. Minute $\mathrm{Pt}$ nanoparticles are then formed in the solution, which act as heterogeneous nucleation sites for $\mathrm{Co}^{26}$ The observed decrease in the mixed potential after $5 \mathrm{~min}$ is consistent with the SEM and XRD analyses of the product; the large precipitates in Fig. $3 \mathrm{a}$ is a mixture of $\mathrm{Co}$ and $\mathrm{CoO}$ (Fig. 4a). However, the large concentration of $\mathrm{CoO}$ in the precipitates cannot be explained by the superficial oxidation of the sample during $\mathrm{XRD}$ measurements and washing. Thus, this $\mathrm{CoO}$ is mainly from intermediate $\mathrm{Co}(\mathrm{II})$ species during the reaction, such as $\mathrm{Co}(\mathrm{OH})_{2}$.

As shown in Fig. 6, the mixed potential gradually decreases from -0.54 to $-1.0 \mathrm{~V}$ with time. $\mathrm{Co}$ (II) ions are then reduced by $\mathrm{N}_{2} \mathrm{H}_{4}$ and Co atoms are deposited preferentially on the surface of Pt nano-

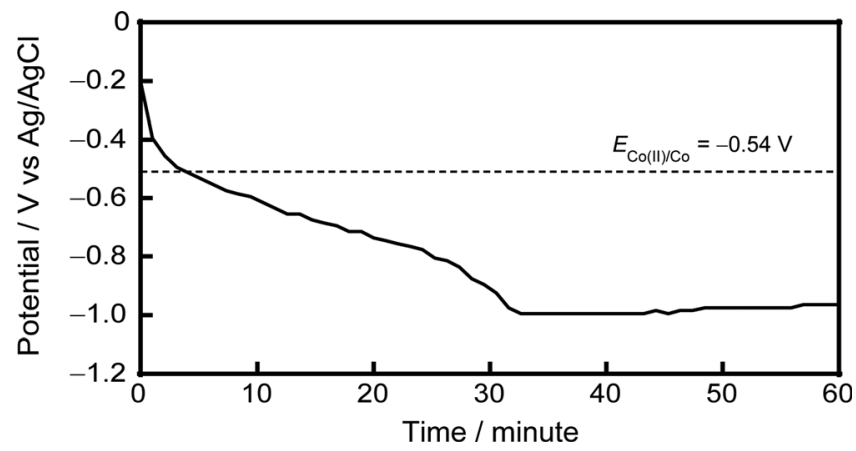

Figure 6. Changes in the mixed potential during electroless deposition of Co in a PG solution at room temperature with $0.087 \mathrm{M} \mathrm{Co}$ (II) acetate, 0.22 $\mathrm{M} \mathrm{NaOH}, 0.22 \mathrm{mM} \mathrm{H}_{2} \mathrm{PtCl}_{6}$, and $0.87 \mathrm{M} \mathrm{N}_{2} \mathrm{H}_{4}$.

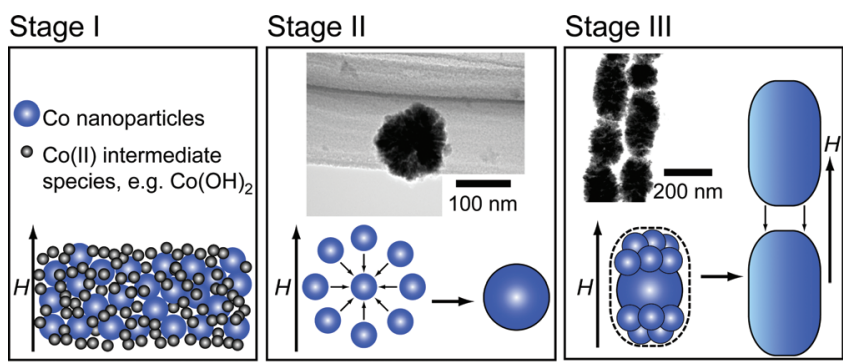

Stage IV

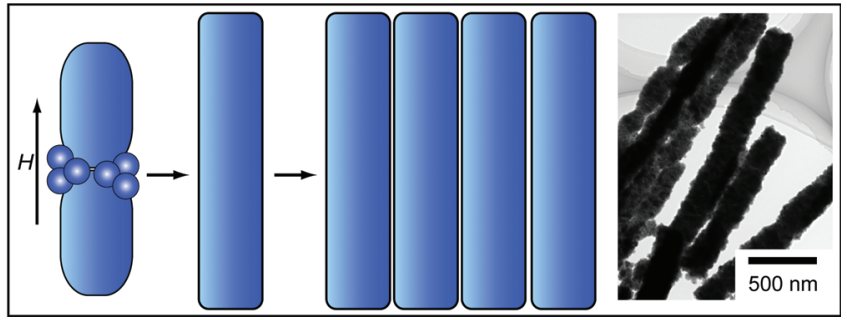

Figure 7. (Color online) Schematic of the formation of Co nanowires by electroless deposition in a PG solution under external magnetic field.

particles. Simultaneously, the intermediate Co(II) species are dissolved in the solution to supply $\mathrm{Co}$ (II) ions. Thus, the mean diameter of the large agglomerated particles at 5 min decreases with time and the Co crystallite size increases since more $\mathrm{Co}$ (II) ions are reduced to metallic Co as is shown in Figs. 3 and 4. After about 20 min reaction, the solution is completely black and the product is primarily metallic Co nanowires. Gas bubbles are also observed, which is primarily $\mathrm{N}_{2}$ and $\mathrm{H}_{2}$ gases due to oxidation of hydrazine and the reductive decomposition of $\mathrm{PG}$.

Formation mechanism of Co nanowires under external magnetic field.-The schematic of the stepwise formation of Co nanowires is illustrated in Fig. 7. At the start of the reaction (stage I), small ferromagnetic Co nanoparticles are precipitated in the solution, regardless of the presence of the magnetic field. These Co nanoparticles are covered by intermediate $\mathrm{Co}(\mathrm{II})$ species, resulting in large agglomerated particles as in Fig. 3a. As more intermediate species are dissolved in the solution, the primary Co nanoparticles become more mobile and are magnetized by the external magnetic field. However, since the dipole magnetic moment of a nanoparticle is proportional to its volume, the magnetic interaction between nanoparticles is too weak to overcome the molecular resistance of viscous solvents, such as $\mathrm{PG}^{20}$ As the reaction proceeds, the primary Co nanoparticles agglomerate and form larger nanoparticles to reduce the surface energy (stage II). Small Co nanoparticles, which are simultaneously generated in the solution, are then heterogeneously nucleated on the surface of these large nanoparticles. In the presence of magnetic fields, the dipole magnetic moments of the nanoparticles would orientate parallel to the field direction, inducing attractive dipolar interactions. Subsequently, Co deposition occurs along the magnetic field and the large Co nanoparticles grow anisotropically to form Co cylinders (stage III) as shown in Fig. $3 b^{28-30}$ With the resulting increase in the dipole magnetic moment per particle, the particle-particle interaction becomes stronger so that they are markedly affected by the external magnetic field. Thus, neighboring Co cylinders start to assemble along the magnetic field at stage III in Fig. 7. With longer reaction time, the small Co nanoparticles that are concurrently produced from the reduction of Co(II) ions are attracted to the linear structures. They deposit especially on the gaps between cylinders to decrease the interfacial energy, leading to the formation of Co nanowires (stage IV). As more Co nanowires are formed in the solution, localized magnetic fields are generated, resulting in the agglomeration of the nanowires. If a stronger 
magnetic field is applied, formation of thick parallel arrays of Co nanowires occurs as in Figs. 1b-1e.

Besides the structure directing role of a magnetic field, several researchers have reported its effect on the crystal growth of metallic nanostructures. ${ }^{6,17,31}$ In the present work, the XRD profiles of the products prepared with and without magnetic field in Fig. 2 show similar intensity ratios and broadening among hcp and fcc Co peaks. This suggests that the magnetic field does not affect the direction of Co crystal growth, which can be due to the fast reduction of $\mathrm{Co}$ (II) ions in the solution. In the current process, Co atoms agglomerate rapidly to form small spherical nanoparticles as primary nanoparticles and, the magnetic field could only influence the assembly of these primary nanoparticles into anisotropic structures. This agrees well with the proposed formation mechanism of nanowires in Fig. 7.

Effects of the concentration of $\mathrm{H}_{2} \mathrm{PtCl}_{6}$ and $\mathrm{N}_{2} \mathrm{H}_{4}$.- Figure 8 shows the SEM images and the corresponding distributions of the wire diameters for the samples prepared with increasing concentration of nucleating agent $\mathrm{H}_{2} \mathrm{PtCl}_{6}$. The wire diameter apparently decreases and the histograms become sharper as the concentration of $\mathrm{H}_{2} \mathrm{PtCl}_{6}$ increases. At a higher concentration of nucleating agent, smaller primary Co nanoparticles are generated, which results in the decrease in the wire diameters. ${ }^{26}$ On the other hand, the mean diameters and lengths of the Co nanowires are reduced to some degree by decreasing the concentration of $\mathrm{N}_{2} \mathrm{H}_{4}$ as shown in Fig. 9. Short nanowires about $4 \mu \mathrm{m}$ long with a mean diameter of about $180 \mathrm{~nm}$ are prepared with $0.43 \mathrm{M} \mathrm{N}_{2} \mathrm{H}_{4}$ in Fig. 9c. At low concentrations of $\mathrm{N}_{2} \mathrm{H}_{4}$, the reduction of $\mathrm{Co}$ (II) ions is slow and a few Co nanoparticles are formed in the solution at a time. Thus, for a constant reaction time of $1 \mathrm{~h}$, smaller Co nanowires are obtained with decreasing concentration of $\mathrm{N}_{2} \mathrm{H}_{4}$. Since high concentrations of $\mathrm{H}_{2} \mathrm{PtCl}_{6}$ and low amounts of $\mathrm{N}_{2} \mathrm{H}_{4}$ result in the size reduction of nanowires, samples are fabricated using $0.087 \mathrm{M} \mathrm{Co}(\mathrm{II})$ acetate, $0.22 \mathrm{M} \mathrm{NaOH}$, $0.43 \mathrm{M} \mathrm{N}_{2} \mathrm{H}_{4}$, and $2.2 \mathrm{mM} \mathrm{H}_{2} \mathrm{PtCl}_{6}$ under $5 \mathrm{~T}$. As shown in Fig. 9d, the Co nanowires appear flexible and fiberlike with a mean diameter of about $110 \mathrm{~nm}$ and an aspect ratio of 600. Although the sample does not look very rigid, the Co nanowires seem to possess some mechanical strength since they retain their morphology even after several ultrasonic washing.

Room-temperature magnetic properties.-Figure 10 shows the $M-H$ plots measured at $300 \mathrm{~K}$ for the products prepared with increasing magnetic field. The presence of hysteresis loops suggests that both Co nanoparticles and nanowires are ferromagnetic at room temperature. The Co nanowires exhibit enhanced magnetic properties with larger $M_{\mathrm{s}}$ and $H_{\mathrm{c}}$ than those of spherical nanoparticles. The saturation magnetizations are determined to be about 57.0, 71.0, and $83.5 \mathrm{emu} \mathrm{g}^{-1}$ for the samples fabricated under 0,5 , and $10 \mathrm{~T}$, (a) $0.022 \mathrm{mM} \mathrm{H}_{2} \mathrm{PtCl}_{6}$

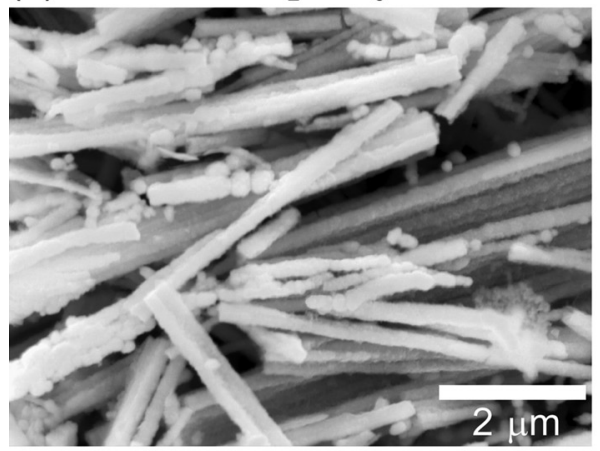

(b) $0.22 \mathrm{mM} \mathrm{H}_{2} \mathrm{PtCl}_{6}$

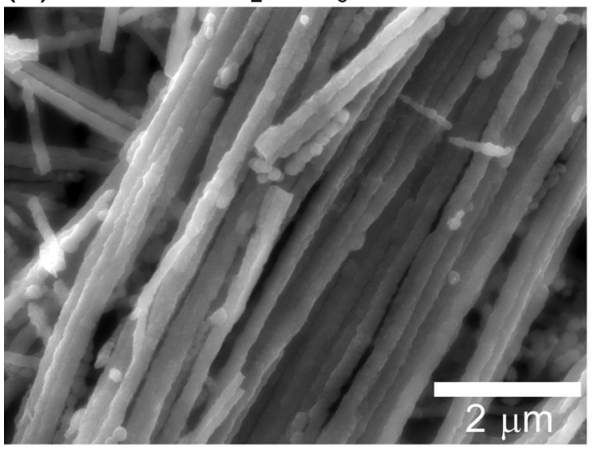

(c) $2.2 \mathrm{mM} \mathrm{H}_{2} \mathrm{PtCl}_{6}$

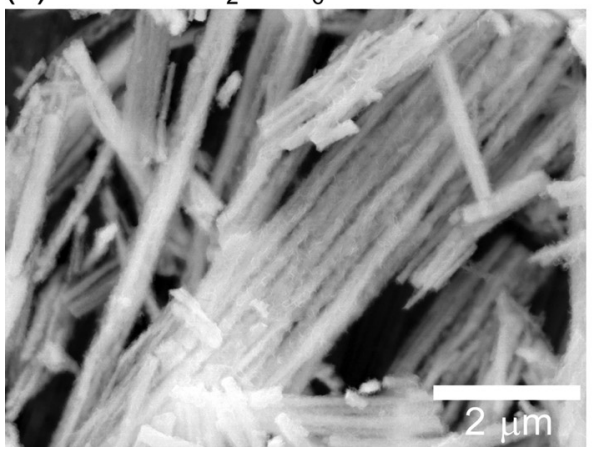

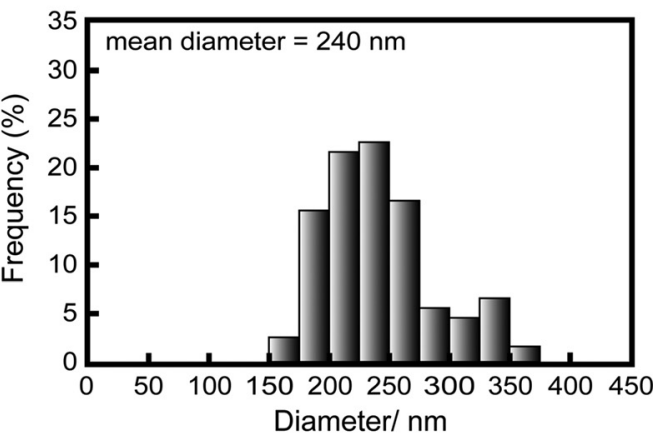

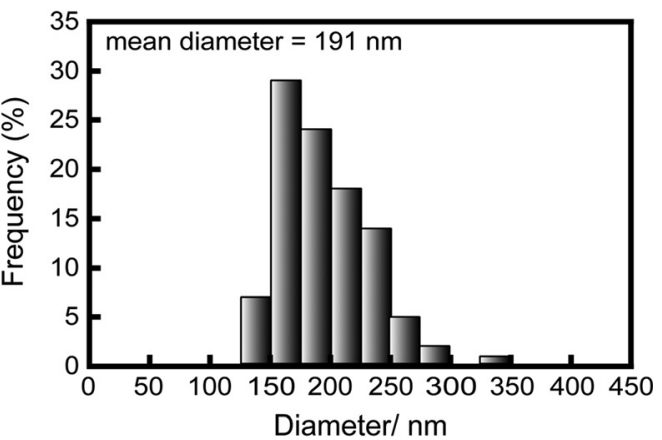

Figure 8. SEM images of Co nanowires prepared in a PG solution containing $0.087 \mathrm{M} \mathrm{Co}(\mathrm{II})$ acetate, $0.22 \mathrm{M} \mathrm{NaOH}$, and $0.87 \mathrm{M} \mathrm{N}_{2} \mathrm{H}_{4}$ by adding (a) 0.022 $\mathrm{mM}$, (b) $0.22 \mathrm{mM}$, and (c) $2.2 \mathrm{mM}$ $\mathrm{H}_{2} \mathrm{PtCl}_{6}$ at room temperature under $5 \mathrm{~T}$. The corresponding size distributions of the samples are also shown.

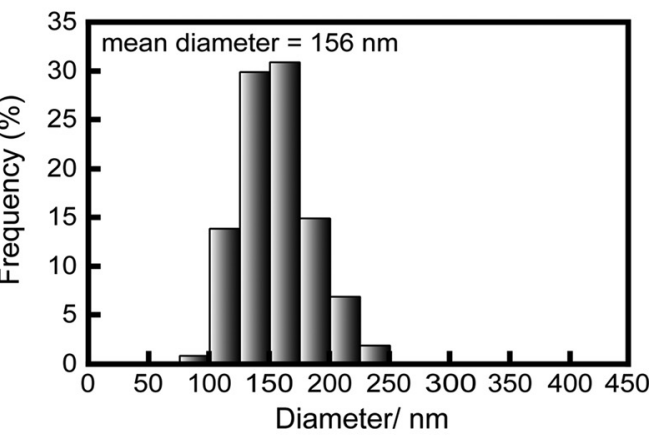


(a)

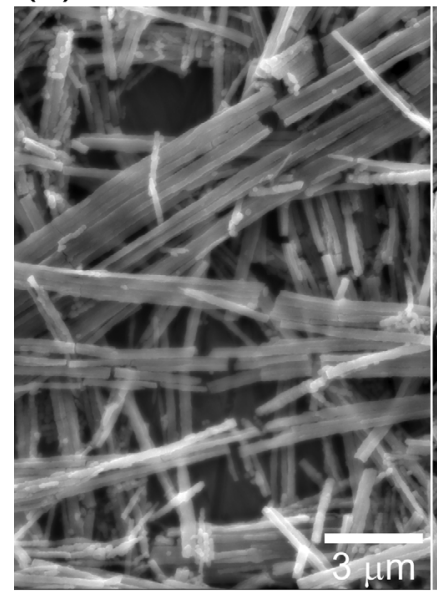

(b)

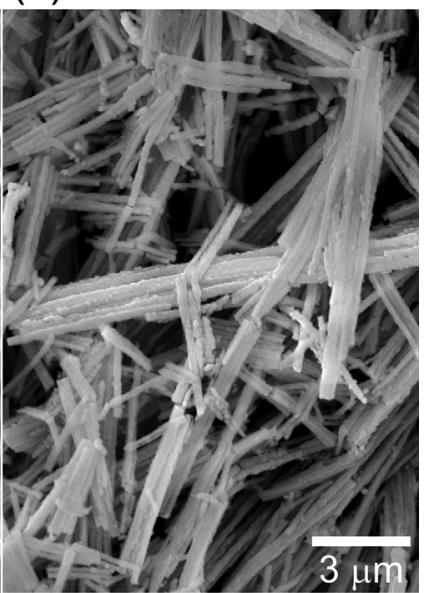

(c)

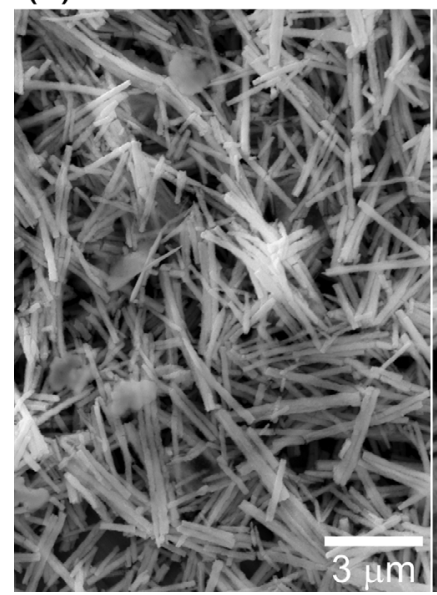

(d)

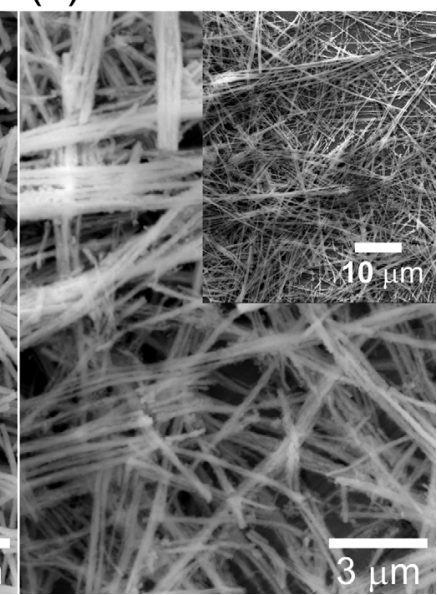

Figure 9. SEM images of Co nanowires synthesized with (a) $0.87 \mathrm{M}$; (b) $0.61 \mathrm{M}$; and (c),(d) $0.43 \mathrm{M} \mathrm{N}_{2} \mathrm{H}_{4}$ at room temperature under 5T. Samples (a)-(c) were prepared in a PG solution with $0.087 \mathrm{M} \mathrm{Co}(\mathrm{II})$ acetate, $0.22 \mathrm{M}$ $\mathrm{NaOH}$, and $0.22 \mathrm{mM} \mathrm{H}_{2} \mathrm{PtCl}_{6}$, whereas sample (d) was prepared in a PG solution containing $0.087 \mathrm{M} \mathrm{Co}(\mathrm{II})$ acetate, $0.22 \mathrm{M} \mathrm{NaOH}$, and $2.2 \mathrm{mM}$ $\mathrm{H}_{2} \mathrm{PtCl}_{6}$.

respectively. All samples, however, have $M_{\mathrm{s}}$ lower than bulk Co $\left(162.5 \mathrm{emu}^{-1}\right){ }^{32}$ This is possibly due to size-effects since spin disorder exists on the surface of metal nanostructures, which could reduce the total magnetic moment. ${ }^{4,33}$ This is also attributed to the superficial oxidation of the products, which may also decrease the saturation magnetization. ${ }^{3}$ On the other hand, the coercivity of Co nanoparticles of about 500 Oe is increased by assembling them to nanowires. The nanowires prepared under 5 and $10 \mathrm{~T}$ exhibit coer-

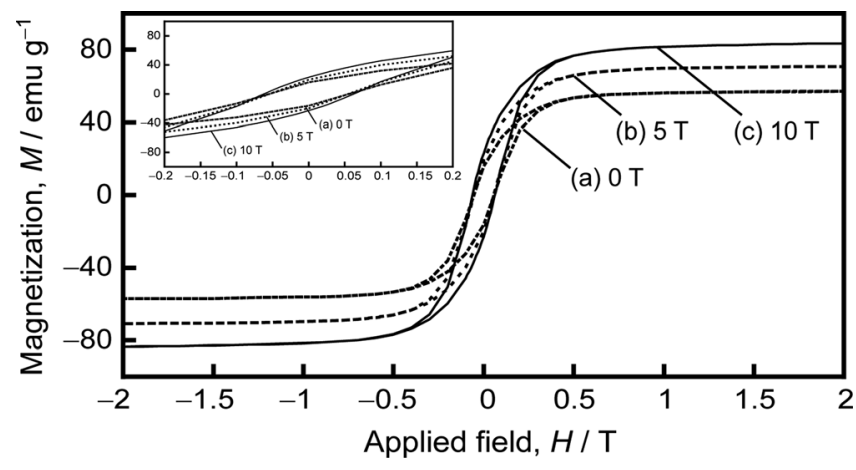

Figure 10. $M-H$ loops measured at $300 \mathrm{~K}$ for products prepared under (a) 0 , (b) 5 , and (c) $10 \mathrm{~T}$. civity values of about 600 and 700 Oe, respectively. This is due to shape anisotropy. ${ }^{32-34}$

\section{Conclusion}

A rapid and simple fabrication process for metallic Co nanowires is presented. Co nanowires with a mean diameter of about $190 \mathrm{~nm}$ and lengths up to $160 \mu \mathrm{m}$ are prepared by electroless deposition in propylene glycol at room temperature under external magnetic field. The formation mechanism of Co nanowires is investigated. Regardless of the magnetic field, small Co nanoparticles are initially formed when the mixed potential of the solution decreases below the measured oxidation-reduction potential of the $\mathrm{Co}(\mathrm{II}) / \mathrm{Co}$ redox pair (about $-0.54 \mathrm{~V}$ vs $\mathrm{Ag} / \mathrm{AgCl}$ ). With longer reaction time, these Co nanoparticles agglomerate to form larger nanoparticles. When the dipole magnetic moments of the large Co nanoparticles are aligned along the magnetic field, attractive dipolar interactions are induced. Subsequently, Co deposition occurs along the magnetic field and the large nanoparticles grow anisotropically, leading to the formation of Co nanowires. Both Co nanoparticles and nanowires are ferromagnetic at room temperature and the Co nanowires have higher $M_{\mathrm{s}}$ and $H_{\mathrm{c}}$ due to shape anisotropy. The size of the nanowires is decreased to a certain degree by increasing the magnetic field strength and concentration of nucleating agent, and by decreasing the amount of reducing agent.

\section{Acknowledgments}

The authors would like to express their gratitude to Associate Professor Tetsu Ichitsubo, Ph.D. from Kyoto University for his guidance and support on experiments under the magnetic field and Mr. Kenji Kazumi from Kyoto University for the assistance in TEM observation. This research was supported by a grant-in-aid for Knowledge Cluster Initiative (Kyoto Nanotechnology Cluster), grant-in-aid for the Global COE Program (International Center for Integrated Research and Advanced Education in Materials Science), and grant-in-aid for Young Scientists (Grant No. B20760505), all from the Japan Society for the Promotion of Science, Ministry of Education, Culture, Sports, Science and Technology of Japan.

Kyoto University assisted in meeting the publication costs of this article.

\section{References}

1. E. K. Athanassiou, P. Grossman, R. N. Grass, and W. J. Stark, Nanotech., 18, 165606 (2007).

2. M. Aslam, R. Bhobe, N. Alem, S. Donthu, and V. P. Dravid, J. Appl. Phys., 98, $074311(2005)$.

3. G. Viau, C. Garcia, T. Maurer, G. Chaboussant, F. Ott, Y. Soumare, and J.-Y. Piquemal, Phys. Status Solidi. A, 206, 663 (2009).

4. G. Zhang, T. Zhang, X. Lu, W. Wang, J. Qu, and X. Li, J. Phys. Chem., 111, 12663 (2007).

5. B.-Y. Xie, Y. Qian, S. Zhang, S. Fu, and W. Yu, Eur. J. Inorg. Chem., 2006, 2454 (2006).

6. H. Niu, Q. Chen, M. Ning, Y. Jia, and X. Wang, J. Phys. Chem. B, 108, 3996 (2004).

7. X. W. Lou, D. Deng, J. Y. Lee, J. Feng, and L. A. Archer, Adv. Mater., 20, 258 (2008).

8. K. T. Nam, D.-W. Kim, P. J. Yoo, C.-Y. Chiang, N. Meethong, P. T. Hammond, Y.-M. Chiang, and A. M. Belcher, Science, 312, 885 (2006).

9. Y. Li, B. Tan, and Y. Wu, Nano Lett., 8, 265 (2008).

10. K. Valenzuela, S. Raghavan, P. A. Deymier, and J. Hoying, J. Nanosci. Nanotechnol., 8, 1 (2008).

11. X. Yuan, C. Du, G. Sun, and N. Pan, Appl. Surf. Sci., 253, 4546 (2007).

12. N. B. Chaure, P. Stamenov, F. M. F. Rhen, and J. M. D. Coey, J. Magn. Magn. Mater., 290-291, 1210 (2005).

13. L. Vila, P. Vincent, L. Dauginet-De Pra, G. Pino, E. Minoux, L. Gangloff, S. Demoustier-Champagne, N. Sarazin, E. Ferain, R. Legras, L. Piraux, and P. Legagneux, Nano Lett., 4, 521 (2004)

14. A. Kazadi Mukenga Bantu, J. Rivas, G. Zaragoza, M. A. Lopez-Quintela, and M. C. Blanco, J. Appl. Phys., 89, 3393 (2001).

15. J. Wang, M. Yao, C. Xu, Y. Zhu, G. Xu, and P. Cui, Mater. Lett., 62, 3431 (2008).

16. C. Gong, J. Tian, T. Zhao, Z. Wu, and Z. Zhang, Mater. Res. Bull., 44, 35 (2009).

17. C. Gong, L. Yu, Y. Duan, J. Tian, Z. Wu, and Z. Zhang, Eur. J. Inorg. Chem., 2008, 2884 (2008).

18. H. Wang, Q.-W. Chen, L.-X. Sun, H. Qi, S. Zhou, and J. Xiong, Langmuir, 25, 7135 (2009). 
19. M. Wu, G. Liu, M. Li, P. Dai, Y. Ma, and L. Zhang, J. Alloys Compd., 491, 689 (2010)

20. M. J. Hu, B. Lin, and S. H. Yu, Nano. Res., 1, 303 (2008).

21. H. Li and S. Liao, J. Mater. Chem., 19, 5207 (2009).

22. H. Niu, Q. Chen, H. Zhu, Y. Lin, and X. Zhang, J. Mater. Chem., 13, 1803 (2003).

23. A. K. Srivastava, S. Madhavi, and R. V. Ramanujan, Appl. Phys. A, 98, 821 (2010).

24. F. Jia, L. Zhang, X. Shang, and Y. Yang, Adv. Mater., 20, 1050 (2008)

25. S. Yagi, M. Kawamori, and E. Matsubara, Electrochem. Solid-State Lett., 13, E1 (2010)

26. M. D. L. Balela, S. Yagi, and E. Matsubara, Electrochem. Solid-State Lett., 13, D4 (2010)
27. F. Bonet, C. Guéry, D. Guyomard, R. Herrera Urbina, K. Tekaia-Elhsissen, and J.-M. Tarascon, Solid State Ionics, 126, 337 (1999).

28. F. Wang, H. Gu, and Z. Zhang, Mater. Res. Bull., 38, 347 (2003).

29. J. Park, Y. Jun, J. Choi, and J. Cheon, Chem. Commun., 2007, 5001 (2007).

30. H. Hu and K. Sugawara, Chem. Phys. Lett., 477, 184 (2009).

31. L. Sun, Q. Chen, Y. Tang, and Y. Xiong, Chem. Commun., 2007, 2844 (2007).

32. B. D. Cullity, Introduction to Magnetic Materials, pp. 400-523, Addison-Wesley, London (1972).

33. R. H. Kodama, J. Magn. Magn. Mater, 200B, 359 (1999).

34. Y. Soumare, J.-Y. Piquemal, T. Maurer, F. Ott, G. Chaboussan, A. Falqui, and G. Viau, J. Mater. Chem., 18, 5696 (2008). 